\title{
STRESS, INDEKS MASSA TUBUH (IMT) DENGAN KEJADIAN HIPERTENSI PADA LANSIA DI KABUPATEN MALANG
}

\author{
Lilik Supriati \\ Staff Pengajar Jurusan Keperawatan Fakultas Kedokteran Universitas Brawijaya \\ Jl. Veteran Malang \\ email: Iylyiex@yahoo.co.id
}

\begin{abstract}
The elderly was the last human development phase causing change on all aspects of physical ,psychological , social and economic. The most problem of physical disorders in elderly was hypertension. Hypertension was condition that systole blood pressure higher than $140 \mathrm{mmHg}$ relating to psychological stress. Other modification factor relating to hypertension prevalence was the body mass index. The purpose of this research knew the relation between stress and body mass index to hypertension prevalence. The method used analytic correlational with cross sectional design. Techniques sampling used purposive sampling included 81 respondents. Research instruments variable stress used quisioner modification of HARS. BMI and blood pressure was obtained through assessing directly. Statistical analysis used the correlation spearman. The result showed that stress elderly mostly in category moderate stress. Mean of score BMI is 23,53 that in nomal category (60,49\%). Based on the bivariat statistic show there is significant relation between stress with hypertension $(r=0,723)$ and there is significant correlation between BMI with hypertension $(r=0,486)$. The Nurse must do implementation stress management in elderly to lower the risk of a rise in blood pressure like techniques of relaxation progressive and nurse must give information to elderly to control weight to prevent increasing in BMI with the activity like doing sports and having good eating habit.
\end{abstract}

Keywords : stress, body mass index, hypertension

Abstrak : Lansia merupakan fase tahap tumbuh kembang terakhir manusia menyebabkan perubahan pada semua aspek fisik, psikologis, sosial dan ekonomi. Permasalahan gangguan fisik terbanyak lansia adalah hipertensi.Kejadian Hipertensi pada lansia dengan kondisi peningkatan tekanan darah sistol > $140 \mathrm{mmHg}$ berkaitan dengan kondisi psikologis stress lansia. Faktor modifikasi lain yang berkaitan dengan kejadian hipertensi adalah indeks masa tubuh. Tujuan penelitian ini mengetahui hubungan stress dan IMT dengan kejadian hipertensi. Rancangan penelitian ini adalah analitik korelasional dengan pendekatan cross sectional. Teknik sampling menggunakan purposive sampling dengan jumlah 81 responden. Instrumen penelitian variabel stress dengan menggunakan kuisioner modifikasi HARS. IMT dan tekanan darah didapatkan dengan melakukan pengukuran langsung kepada lansia. Analisis statistik menggunakan uji korelasi spearman. Hasil penelitian menunjukkan bahwa stress lansia sebagian besar dalam kategori stress sedang (53,53\%), rata-rata score IMT sebesar 23,53 dengan kategori normal (60,49\%). Berdasarkan uji bivariat menunjukkan ada hubungan signifikan antara stress dengan kejadian hipertensi $(r=0,723)$ dan ada hubugan signifikan IMT dengan hipertensi $(r=0,486)$. Untuk itu perlu melakukan manajemen stress lansia untuk menurunkan resiko peningkatan tekanan darah seperti teknik relaksasi progresif serta pengontrolan berat badan lansia untuk mencegah peningkatan IMT dengan aktivitas olah raga dan pola makan yang baik.

Kata kunci : stress, indeks masa tubuh, kejadian hipertensi

\section{PENDAHULUAN}

Lanjut usia merupakan salah satu tahap tumbuh kembang terakhir dalam siklus hidup manusia yang mengalami banyak perubahan secara fisik, mental, sosial, dan ekonomi (Tamher \& Noorkasiani, 2009; Fatmah, 2010). Jumlah penduduk lansia di Indonesia Indonesia diprediksi pada tahun 2020 sebesar 11,34\% (28,8 juta jiwa) (Fatmah, 2010). Lansia akan mengalami peningkatan jumlah lebih dari $250 \%$ di negara-negara berkembang, sedangkan di Negara maju akan mengalami peningkatan 71\% (WHO, 2011). Hal ini tentunya akan diikuti dengan prevalensi kejadian penyakit degeneratif seperti hipertensi. Kejadian hipertensi di negara berkembang 
termasuk Indonesia diperkirakan pada tahun 2025 sekitar 80\% dari 639 juta kasus ditahun 2000 menjadi 1,15 milyar (Armilawaty et al., 2007). Hipertensi merupakan faktor risiko utama kardiovaskuler yang merupakan penyebab utama kematian di seluruh dunia. Peningkatan umur harapan hidup dan perubahan gaya hidup akan meningkatkan faktor risiko hipertensi di berbagai negara. Berdasarkan data Survei Kesehatan Rumah Tangga, di Indonesia pada tahun 2004 prevalensi hipertensi di pulau Jawa 41,9\%, dengan kisaran dimasing-masing provinsi 36,6\% - 47,7\%. (Depkes RI, 2009).

Hipertensi banyak terjadi pada usia lanjut. Hal ini berkaitan dengan kualitas tidur lansia yang cenderung buruk akibat permasalahan psikologis lansia. Masalah kesehatan jiwa yang biasa dialami lansia antara lain berupa cemas, kesepian, perasaan sedih, dan mudah tersinggung. Kondisi munculnya permasalahan psikologis lansia ini merupakan akibat dari respon stress yang tidak terselesikan dengan baik (Maryam dkk., 2008). Peningkatan stress yang berkepanjangan pada lansia akan menyebabkan keseimbangan tubuh terganggu seperti peningkatan tekanan darah (Sani ,dkk, 2008). Stress dan hipertensi memiliki hubungan timbal balik dimana penyakit hipertensi sendiri juga bisa menjadi penyebab peningkatan stress pada lansia karena ketidak mampuan dalam penyesuaian diri terhadap terapi, kepatuhan diet serta ketakutan lansia terhadap dampak komplikasi hipertensi yang dialami. Demikian juga stress yang dialami lansia juga akan meningkatkan resiko terjadinya hipertensi.

Faktor lain yang dapat dimodifikasi lainnya yang berkaitan dengan terjadinya hipertensi adalah Indeks Massa Tubuh (IMT). IMT merupakan perbandingan standar berat terhadap tinggi badan yang sering digunakan sebagai indikator kesehatan secara umum. Angka IMT antara 18,5 dan 24,9 dianggap normal, dimana IMT yang lebih tinggi mungkin mengindikasikan kelebihan berat badan atau obesitas. Overweight merupakan keadaan patologis sebagai akibat dari konsumsi makanan yang jauh melebihi kebutuhannya sehingga terdapat penimbunan lemak yang berlebihan dari yang diperlukan untuk fungsi tubuh (Soetjiningsih, 2004). Angka prevalensi overweight di Indonesia sebagai Negara berkembang juga menunjukkan angka yang cukup tinggi. Data Riskesdas pada tahun 2007 mencatat dari 200 juta penduduk Indonesia mengalami overweight sebesar $17,5 \%$ dan obesitas $4,7 \%$.

Peningkatan prevalensi overweigh takan meningkatkan prevalensi hipertensi pada lansia. Indek massa tubuh membantu menentukan apakah seseorang berisiko terkena penyakit yang berhubungan dengan berat badan seperti hipertensi (Stevanustanly, 2009). IMT berkorelasi dengan tekanan darah, terutama tekanan darah sistolik. Risiko relatif untuk menderita hipertensi pada orang dengan IMT>25 adalah lima kali lebih tinggi dibandingkan dengan seseorang yang berat badannya normal (Muhammadun, 2010). Beberapa studi menunjukkan bahwa resiko yang paling rendah untuk penyakit kardiovaskuler adalah mereka yang mempunyai nilai IMT 21-25, risiko akan meningkat jika nilai IMT 25-27, risiko nyata jika IMT 27-30, risiko sangat menonjol jika IMT > 30 (Siburian, 2007). IMT dapat digunakan untuk menentukan seberapa besar seseorang dapat terkena risiko penyakit tertentu yang disebabkan karena berat badannya.Berat badan berlebih merupakan faktor presdiposisi penting terjadinya hipertensi. Penurunan berat badan sebesar $5 \mathrm{~kg}$ pada penderita hipertensi dengan obesitas dapat menurunkan tekanan darah. (Joewono, 2003). Salah satu yang dapat digunakan sebagai indikator overweight dan obesitas dengan menggunakan IMT.

Penelitian ini bertujuan untuk mengetahui hubungan stress dengan kejadian hipertensi serta mengetahui hubungan IMT dengan kejadian hipertensi pada lansia di Desa Kedungrejo Kabupaten Malang. Berdasarkan studi pendahuluan didapatkan data bahwa jumlah lansia di wilayah ini sekitar 2.534 jiwa dengan pembagian 3 kelompok umur yaitu pra lansia, (45-59 tahun), lansia (6069 tahun) dan lansia resiko tinggi ( lebih dari 70 tahun) yang berdasarkan data kunjungan ke puskesmas didapatkan 
penyakit terbanyak adalah hipertensi. Berdasarkan wawancara dengan 20 lansia didapatkan 15 orang mengatakan sering mengalami gangguan tidur, mengeluh pusing, sering marah yang merupakan tanda dan gejala respon stress.

\section{METODE PENELITIAN}

Rancangan penelitian ini adalah analitik korelasional dengan pendekatan cross sectional. Teknik sampling menggunakan purposive sampling. Populasi dan sampel penelitian adalah lanjut usia dengan usia 45 tahun ke atas atau kategori usia minimal pralansia, tidak menderita penyakit kardiovaskular seperti stroke, DM dan kelainan jantung, serta tidak mengalami gangguan jiwa berat. Jumlah sampel sebanyak 81 responden.
Instrumen penelitian yang digunakan yaitu kuisioner modifikasi HARS untuk variabel stress, sedangkan IMT dan tekanan darah dilakukan dengan pengukuran. Analisis statistik menggunakan analisis univariat untuk data sosiodemografi dan data khusus penelitian seperti mean, median, standar deviasi untuk data bersifat numerik, sedangkan data kategorik berupa frekuensi dan prosentase. Analisis bivariat dengan menggunakan spearman dengan bantuan program SPSS.

\section{HASIL PENELITIAN}

Hasil penelitian ditampilkan berdasarkan analisis univariat dan bivariat.

\section{Analisis Univariat}

Tabel 1. Karakteristik Responden Berdasarkan Usia

\begin{tabular}{cccccc}
\hline No & Karakteristik & $\mathbf{n}$ & Mean & Median & Standar deviasi \\
\hline 1 & Usia & 81 & 57,88 & 58 & 12,29 \\
\hline & & & \multicolumn{3}{c}{ Sumber: data primer, 2017 }
\end{tabular}

Tabel 2. Karakteristik Responden Berdasarkan Jenis Kelamin, Status Pernikahan Dan Pekerjaan

\begin{tabular}{cccc}
\hline No & Karakteristik & $\mathbf{F}$ & $\%$ \\
\hline 1 & Jenis kelamin Lansia & & \\
\hline \multicolumn{5}{c}{ a. Laki-laki } & 25 & $30,86 \%$ \\
\hline 2 & b. Perempuan & 56 & $69,14 \%$ \\
\hline \multicolumn{5}{c}{ Pekerjaan } & 36 & $44,44 \%$ \\
\hline 3 & a. Bekerja & 45 & $55,55 \%$ \\
\hline & b. Tidak bekerja & & $41,97 \%$ \\
\hline & Status Pernikahan & 34 & $58,02 \%$ \\
\hline & a. Menikah & 47 & Sumber: data primer, 2017
\end{tabular}

Tabel 3 Karakteristik responden BerdasarkanBerat Badan dan Tinggi Badan

\begin{tabular}{ccccc}
\hline No & Karakteristik & Mean & Median & St Deviasi \\
\hline 1 & Berat Badan & 56,60 & 54 & 16,19 \\
\hline 2 & TinggiBadan & 151,40 & 153 & 12,85 \\
\hline & & \multicolumn{3}{c}{ Sumber data primer, 2017 }
\end{tabular}

Tabel 4 Karakteristik responden Berdasarkan Tekanan Darah

\begin{tabular}{ccccc}
\hline No & Karakteristik & Mean & Median & St Deviasi \\
\hline 1 & TD Sistole & 139,88 & 140 & 22,27 \\
\hline 2 & TD Diastole & 85,19 & 80 & 12,46 \\
\hline & & \multicolumn{2}{c}{ Sumber data primer, 2017 }
\end{tabular}


Pada karakteristik responden (tabel 1, 2, 3 dan 4 ) didapatkan data ratarata usia lansia adalah 57,88 tahun. Sebagian besar lansia adalah perempuan sebanyak 56 responden $(69,14 \%)$, sebagian besar tidak bekerja sebanyak 45 orang $(55,55 \%)$ dan sebagian besar berstatus janda / duda sebanyak 47 orang ( 58,02\%). Rata- rata tingi badan lansia
151, $40 \mathrm{~cm}$ dan rata rata berat badan lansia adalah 56,60 kg. Karakteristik tekanan darah lansia didapatkan rata rata tekanan darah sistole sebesar 139,88 $\mathrm{mmHg}$ dan rata-rata tekanan darah diastole adalah $85,19 \mathrm{mmHg}$

Untuk data khusus penelitian dijabarkan dalam tabel 5 .

Tabel 5 Distribusi Variabel Stres Lansia

\begin{tabular}{ccc}
\hline Variabel Stres & $\mathbf{N}$ & $\%$ \\
\hline Stres tinggi & 19 & $23,50 \%$ \\
Stres sedang & 33 & $53,53 \%$ \\
Stres rendah & 29 & $46,60 \%$ \\
Total & 81 & $100 \% \%$ \\
\hline
\end{tabular}

Berdasarkan tabel 5 dapat dijelaskan bahwa pada variabel stress lansia didapatkan sebagian besar lansia

mengalami stress sedang sejumlah 33 orang ( $53,53 \%)$.

Tabel 6.Distribusi Variabel Indek Massa Tubuh Lansia

\begin{tabular}{cccccc}
\hline No & Variabel & $\mathbf{n}$ & Mean & Median & Standar deviasi \\
\hline 1 & Score IMT & 81 & 23,53 & 23 & 4,65 \\
\hline & & & & \\
\hline & Kategori IMT & $\mathbf{n}$ & $60,49 \%$ \\
& Normal & 49 & $32,10 \%$ \\
& Overweight & 6 & $7,41 \%$ \\
Obese & 81 & $100 \%$ \\
Total & & & Sumber: data primer, 2017
\end{tabular}

Berdasarkan tabel 6 dapat diketahui bahwa rata-rata score indek masa tubuh sebesar 23,53 dengan media sebesar 23 dengan kategori IMT sebagian besar berada dalam kategori IMT normal sebanyak 49 orang $(60,49 \%)$.

Tabel 7. Distribusi Variabel Kejadian Hipertensi

\begin{tabular}{ccc}
\hline Kejadian Hipertensi & $\mathbf{n}$ & $\%$ \\
\hline Normal & 44 & $54,32 \%$ \\
Pre hipertensi & 10 & $12,34 \%$ \\
Stage 1 & 13 & $16,04 \%$ \\
Stage 2 & 11 & $13,58 \%$ \\
Crisis & 3 & $3,70 \%$ \\
Total & 81 & $100 \%$ \\
\hline
\end{tabular}




\section{Analisis Bivariat}

Tabel 8 menggambarkan hasil analisis bivariat dengan menggunakan uji hipotesis korelasi spearman

Tabel 8 Hasil Analisis Bivariat

\begin{tabular}{cccc}
\hline Variabel & $\mathbf{r}$ & $\mathbf{p}$ & Keterangan \\
\hline Stres - kejadian hipertensi & 0,723 & 0,001 & Signifikan \\
IMT - kejadian hipertensi & 0,486 & 0,004 & Signifikan \\
\hline
\end{tabular}

Berdasarkan tabel 8 didapatkan bahwa ada hubungan antara stres dengan kejadian hipertensi lansia $(r=0,723)$ dengan kekuatan hubungan kuat dan arah positif. Variabel IMT dengan kejadian hipertensi juga menunjukkan ada korelasi signifikan dengan kekuatan cukup kuat ( $r$ $=0,486$ ) dengan arah positif.

\section{PEMBAHASAN}

\section{Hubungan Stres Dengan Kejadian Hipertensi Pada Lansia}

Hasil penelitian (tabel 5) menunjukkan bahwa stress lansia didapatkan sebagian besar mengalami stress sedang sejumlah 33 orang ( $53,53 \%)$. Stress merupakan bagian integral dalam kehidupan manusia. Hampir sebagian individu dalam kehidupannya pernah mengungkapkan secara subyektif terhadap perasaan yang tidak spesifik berupa kesulitan dan kesusahan akibat ancaman eksternal yang berbahaya (Fortinash dan Warret (2006). Stress pada lansia berkaitan penurunan aspek fisik, perubahan kemampuan aktivitas social dan ekonomi termasuk masa pensiun dan kehilangan pasangan atau orang yang berarti.

Berdasarkan faktor status kesehatan, kondisi yang semakin menua akan timbul masalah kesehatan yang menjadi stressor pada lansia. Demikian juga kondisi stress yang berkepanjangan akan menyebabkan terganggunya kesehatan fisik lansia. Hal ini menunjukkan bahwa stress dapat memicu terjadinya gangguan fisik, demikian pula adanya gangguan fungsional tubuh dapat menjadi stresor terjadinya stress. Berdasarkan uji korelasi pada tabel 8 menunjukkan bahwa ada hubungan yang signifikan antara stres dengan kejadian hipertensi lansia $(r=0,723)$ dengan kekuatan hubungan kuat dan arah positif. Hal ini menunjukkan bahwa semakin tinggi stress maka semakin tinggi juga tekanan darah yang berarti bahwa semakin beresiko terjadi hipertensi.

Hipertensi adalah suatu gangguan pada pembuluh darah yang mengakibatkan suplai oksigen dan nutrisi, yang dibawa oleh darah terhambat sampai ke jaringan tubuh yang membutuhkan. Hipertensi diartikan sebagai peningkatan tekanan darah secara terus menerus sehingga melebihi batas normal. Hipertensi merupakan produk dari resistensi pembuluh darah perifer dan kardiak output (Smeltzer, 2002).

Sistem saraf otonom terdiri dari dua sub sistem yaitu sistem saraf simpatis dan sistem saraf parasimpatis yang kerjanya saling berlawanan. Sistem saraf simpatis lebih banyak aktif ketika tubuh membutuhkan energi misalnya pada saat terkejut, takut, cemas atau berada dalam kondisi tegang. Pada kondisi seperti stres, sistem saraf akan memacu aliran darah ke otot-otot skeletal, meningkatkan denyut jantung, napas menjadi cepat, dan tekanan darah meningkat (Prawitasari, 2002).

Pada saat seseorang mengalami kejadian nyata atau potensial yang mengancam kesehatan maka akan terjadi respon sistem saraf simpatis yang berarti sebagai respon fight-flight. Hal ini termasuk dilatasi pupil, pernapasan meningkat, peningkatan denyut jantung, dan ketegangan pada otot (Synder \& Lindquist, 2002). Respon ini membantu manusia dalam mengatasi situasi stress- 
full jangka pendek. Namun jika stres yang diterima berlangsung terus-menerus maka respon psiko fisiologikal yang berulang dapat menimbulkan efek yang membahayakan tubuh. Brown (1997, dalam Synder \& Lindquist, 2002) menyebutkan bahwa respon stress adalah bagian dari jalur umpan balik yang tertutup antara otot-otot dan pikiran. Penilaian terhadap stressor mengakibatkan ketegangan otot yang mengirimkan stimulus ke otak dan membuat jalur umpan balik.

\section{Hubungan Indeks Masa Tubuh dengan Kejadian Hipertensi Pada Lansia}

Hasil penelitian menunjukkan bahwa rata-rata skor IMT lansia adalah 23,53 dan sebagian besar berada dalam IMT normal. IMT merupakan perbandingan standar berat terhadap tinggi badan yang sering digunakan sebagai indikator kesehatan secara umum. Angka IMT antara 18,5 dan 24,9 dianggap normal, IMT yang lebih tinggi mengindikasikan bahwa individu mengalami kelebihan berat badan (over weight) maupun obesitas.

Menurut Riskesdas tahun 2007, faktor resiko yang paling utama penyebab hipertensi adalah kegemukan. Penilaian yang digunakan dalam menentukan status gizi dengan menggunakan Indeks massa tubuh. Meningkatnya berat badan, akan meningkatkan kebutuhan darah untuk suplai oksigen ke jaringan tubuh. Peningkatan volume darah dalam sirkulasi pembuluh darah akan meningkatkan tekanan darah pada dinding arteri.

Hasil penelitian menunjukkan hubungan yang signifikan antara IMT dengan kejadian hipertensi dengan kekuatan sedang dengan arah positif artinya bahwa semakin tinggi score IMT maka tekanan darah juga akan semakin tinggi yang berarti bahwa resiko terjadinya hipertensi semakin meningkat. Hipertensi sangat umum terjadi pada orang gemuk. Para

\section{DAFTAR PUSTAKA}

Abdi, I.A. 2009. Memahami Krisis lanjut Usia : Uraian Medis dan Pedagogis. Jakarta : PT. Gunung Mulia. peneliti di Norwegia menyebutkan bahwa peningkatan tekanan darah lebih sering terjadi pada orang dengan obesitas. Peningkatan tekanan darah juga mudah terjadi pada orang gemuk tipe apel (central obesity, konsentrasi lemak pada perut) bila dibandingkan dengan mereka yang gemuk tipe buah pear (konsentrasi lemak pada pinggul dan paha), (Munger, 2009). Penelitian terakhir menunjukan bahwa resiko terkena penyakit jantung koroner pada orang gemuk tiga sampai empat kali lebih tinggi bila dibandingkan dengan orang normal. Setiap peningkatan 1 kilogram berat badan terjadi peningkatan kematian akibat penyakit jantung coroner sebanyak 1\% ( Munger, 2009 ).

\section{KESIMPULAN}

Berdasarkan hasil penelitian dapat disimpulkan bahwa ada hubungan yang bermakna antara stress dengan kejadian hipertensi pada lansia dengan kekuatan hubungan kuat dan arah positif yang berarti semakin tinggi stress maka tekanan darah semakin tinggi (resiko hipertensi semakin tinggi. Demikian juga terdapat hubungan yang siginifikan antara IMT dengan kejadian hipertensi dengan korelasi sedang dan arah positif.

Untuk meminimalkan resiko terjadinya peningkatan tekanan darah pada lansia maka perlu untuk melakukan manajemen stres lansia seperti teknik relaksasi progresif, guided imagery dan perlu adanya sarana lansia untuk mengembangkan aktivitas sebagai sara sosialisasi untuk menurunkan masalah psikologis akibat kesepian dan kehilangan pasangan atau orang berarti. selain itu perlu untuk mengendalikan keseimbangan berat badan agar tidak terjadi obesitas dan overweight sehingga menurunkan resiko peningkatan tekanan darah.

Copstead, L.C. \& Banasik, J.L. (2000). Pathofisiology ( $2^{\text {nd }}$ ed).Philadelphia : W.B. Saunders Company. 
Darmojo, R.B., Martano, H.H. 2006. Buku Ajar Geriatri: IImu Kesehatan Usia Lanjut Edisi 3. Jakarta: Balai penerbit FKUI Press.

Depkes RI. (2008). Profil Kesehatan Indonesia. Jakarta : Depkes RI.

Fortinash, K.M \& Worret, P.A.H. (2004). Psychiatric mental health nursing. $\left(3^{\text {rd }}\right.$ ed). St. Louis: Mosby.

Maryam, SR. (2008). Mengenal usia lanjut dan perawatannya. Jakarta : Salemba Medika

Prawitasari, Johana E. (2002). Psikoterapi: pendekatan konvensional dan kontemporer. Yogyakarta: Unit Publikasi Fakultas Psikologi UGM.

Riskesdas., 2007. Jakarta : Badan Penelitian dan Pengembangan Kesehatan, Departemen Kesehatan, Republik Indonesia

Rocchini.,2006. Adolescent obesity and hypertension. Childhood Hypertension. Pediatric Clinic North America ; 40:81-92.

Saleh.,2011. Faktor Resiko Kejadian Hipertensi pada Dewasa pedesaan di Kecamatan Rumbia kabupaten Lampung Tahun 2011. Skripsi. Depok : FKMUI

Sarafino. (2000). Health psychology: biopsychosocial interactions. $\quad\left(3^{\text {rd }}\right.$ ed). USA: John Willey \& Sons Inc.

Smeltzer, Suzanne. 2002. Buku Ajar Keperawatan Medikal Bedah Brunner \& Suddarth. Jakarta : EGC
Smeltzer,S.C, \& Bare, B.G. (2008). Brunner \& Suddarth's : textbook of medical surgical nursing. Philadelphia : Lippincott.

Stevanustanly., 2009. Menghitung BMI (Body Mass Index) atau IMT (Indeks Massa Tubuh), Alih Bahasa : Saryono, Yogyakarta : In Books.

Stuart, G.W \& Laraia, M.T. (2005). Principles and practice of psychiatric nursing. ( $\left.8^{\text {th }} \mathrm{ed}\right)$. St. Louis: Mosby.

Suliswati. (2005). Konsep Dasar Keperawatan Kesehatan Jiwa. Jakarta : EGC.

Wahyu, Wiyono dan Arif Widodo, 2010, Hubungan Antara Tingkat Kecemasan Dengan Kecenderungan Insomnia Pada Lansia di Panti Wredha Dharma Bakti Surakarta. Jurnal; Fakultas IImu Kesehatan UMS.

WHO. Obesity and overweight fact sheet. Diakses dari http://www.who.int/mediacentre

Witjasongko., 2008. Nutrition Aspect Hypertension in The Indonesian Elderly. Journal FKM Vol 98.Depok : FKM UI. 